\title{
Visual and Surface Properties of CdTe Thin Films on CdS/FTO Glass Substrates
}

\author{
Ramya K, Yuvaraja T \\ Department of Electrical and Electronics Engineering, Sri Sai Ram College of Engineering, Bangalore, India
}

\begin{tabular}{l}
\hline Article Info \\
\hline Article history: \\
Received Sep 23, 2015 \\
Revised Nov 13, 2015 \\
Accepted Dec 5, 2015 \\
\hline Keyword: \\
Bandgap \\
Cds \\
CDTE Thin Film \\
Solar cell \\
\end{tabular}

\begin{abstract}
Cadmium telluride (CdTe) thin film material was deposited ontop of Cadmium Sulfide (CdS) substrate using vacuum evaporation technique. The sample was characterized using X-ray diffraction (XRD) and UV-VIS-NIR spectroscopy. XRD studies revealed that the sample was polycrystalline in nature. The SEM image showed that the sample is columnar in structure and the grains are uniform. Optical band gap of the CdTe thin film was estimated from transmittance and reflectance data and it was found $1.53 \mathrm{eV}$. The structural, optical and surface properties of the film showed that the CdTe thin film materials can be used for fabrication of CdTe thin film solar cell.
\end{abstract}

\section{Corresponding Author:}

Ramya K

Department of Electrical and Electronics Engineering,

Sri Sai Ram College of Engineering,

Bangalore City, India

Email: ramyaj.k14@gmail.com

\section{INTRODUCTION}

Power generation by solar energy can act as an alternative source of energy in the future. Thin-film solar cells are positioned to become the future of solar energy technology because of their less material usage and lower cost manufacturing processes. Cadmium telluride (CdTe) photovoltaic technology has the potential to become a leading energy producer in the coming decades in solar energy industry. The material can be used as an absorber layer for solar cells for its high absorption co-efficient and optimum band gap [1]. CdTe has favourable physical characteristics for medical applications that have been investigated in the reported paper [2].

The material is considered to be one of the most useful material for the fabrication of X-ray and $\gamma$ ray detectors operating at room temperature due to specific properties of high average atomic number, fine charge-transport properties, high resistivity and relatively large band gap energy [3]. The objectives of the present work are deposition of CdTe thin film on CdS (chemical bath deposited on commercial Fluorinedoped tin oxide (FTO) glass substrates which will be reported later) and characterize the $\mathrm{CdTe} / \mathrm{CdS} / \mathrm{FTO}$ thin films to enrich knowledge about fabrication of thin film solar cell [4].

\section{RESEARCH METHOD}

CdTe film was prepared on CdS/FTO glass substrates at high vacuum $\left(\sim 10^{-6}\right.$ Torr $)$ by the thermal evaporation method.At the high vacuum, the substrate was heated with the help of radiant heater at a certain temperature called substrate temperature or deposition temperature. In the deposition of the thin film, the substrate temperature was $250^{\circ} \mathrm{C}$ and annealing temperature was $100^{\circ} \mathrm{C}$ for 60 minutes. The structural analysis of the film was performed using Philips X'pert PRO X-ray diffractometer [5]. In the experiment, 
$\mathrm{CuK} \alpha$ radiation of wave length, $\lambda=1.54178 \AA$ was used and the angle of diffraction was varied from $20^{\circ}$ to $60^{\circ}$. The grain size (D) of the film was measured from Scherrer formula written below using FWHM $(\beta)$ of the (111) diffraction peak [6].

$$
D=\frac{0.9 \lambda}{\beta \cos \theta}
$$

Here, $\theta$ is the Bragg angle. The lattice parameter was calculated using the following equation

$$
a=d \sqrt{h^{2}+k^{2}+l^{2}}
$$

whereh, $k$ and $l$ represents the Miller indices and $d$ is the inter planer spacing. The micro strain $(\varepsilon)$ and dislocation density $(\rho)$ of the film wasmeasured from the following equations [6].

$$
\begin{aligned}
& \varepsilon=\frac{\beta_{2 \theta} \cos \theta}{4} \\
& \rho=\frac{1}{D^{2}}
\end{aligned}
$$

The surface image of the film was taken using Scanning Electron Microscope (SEM). The optical properties like transmittance, reflectance, and absorption co-efficient and optical band gap were analysed from UV-VISNIR recording spectrophotometer (shimadju, UV03100, Japan) in the photon wave length range from 400 to $2500 \mathrm{~nm}$. The absorption co-efficient $(\alpha)$ was measured from the following formula [7].

$$
\propto=-\frac{\ln T}{\mathrm{t}}
$$

Where $t$ is the thickness of the films and $T$ is the transmittance of the films. The optical band gap energy (Eg) of CdTe was estimated using the following relation

$$
(\alpha \mathrm{h} v)^{2}=(\mathrm{h} v-\mathrm{Eg})
$$

\section{ANALYSIS OF CdTe/CdS/FTO THIN FLIM}

\subsection{Structural Study of CdTe/CdS/FTO Thin Film}

X-ray diffraction (XRD) patterns of CdTe thin film study of different substrates and thickness are shown in figure 1 . The peaks at $2 \theta=23.83^{\circ}, 26.69^{\circ}, 30.31^{\circ}, 35.40^{\circ}, 39.39^{\circ}, 46.50^{\circ}, 50.70^{\circ}, 57.02^{\circ}$ and $62.59^{\circ}$ are found in figure 1(a). These peaks corresponds to reflection from (111), (200), (101), (220), (311), (112), (400) and (331) planes CdTe cubic structure, respectively. The figure 1(b) and figure 1(c) showed CdTe cubic structure. The results of the structural parameters of CdTe thin films have also been tabulated in table 1. The data presented in table $1(\mathrm{CdTe} / \mathrm{CdS} 1000 \mathrm{~nm}$ and $\mathrm{CdTe} / \mathrm{CdS} 1300 \mathrm{~nm})$ are comparable with the earlier reports in table $1(\mathrm{CdTe} 1000 \mathrm{~nm})$. All peaks reflected in the XRD patterns are in good agreement with other reported paper [8] as well. The observed $\mathrm{d}$ values in figure 1 are well matches with standard $\mathrm{d}$ values [9]. The figure- 1 showed that the film CdTe/CdS $1000 \mathrm{~nm}$ is more crystalline than CdTe $1000 \mathrm{~nm}$ thin film. In figure-1, the film $\mathrm{CdTe} / \mathrm{CdS} 1000 \mathrm{~nm}$ showed more reflection peaks than $\mathrm{CdTe} / \mathrm{CdS} 1300 \mathrm{~nm}$ thin film. The CdTe/CdS $1000 \mathrm{~nm}$ samples relative intensity ratio of (111), (220), (311) (400) and (331) planes are 100, $57.09,28.44,2.66$ and 4.45 and the values are comparable to the standard value of 100, 62, 28, 5 and 9 respectively. No diffraction peak corresponding to metallic $\mathrm{Cd}$, Te, or other compounds was observed. The XRD analysis revealed that the all films are polycrystalline in nature and crystalinity is improved. The lattice parameter was calculated to be $6.482 \AA$ which is very close to the standard value of $6.481 \AA$. The calculated values agree well with that of reported values [10]. The calculated average grain size was about 23-48 $\mathrm{nm}$. This was in close agreement with that of CdTe films where a smaller average grain size $(24 \mathrm{~nm})$ was reported [11]. The larger grain size is an important factor to increase photovoltaic efficiency. Where, $h v$ is the incident photon energy. The thickness of the film was measured by insituFTM5 quartz crystal thickness monitor 
(Edwards, UK). If density of the material is known, the rate of deposition, which is different for different elements, can be controlled using the monitor [12].
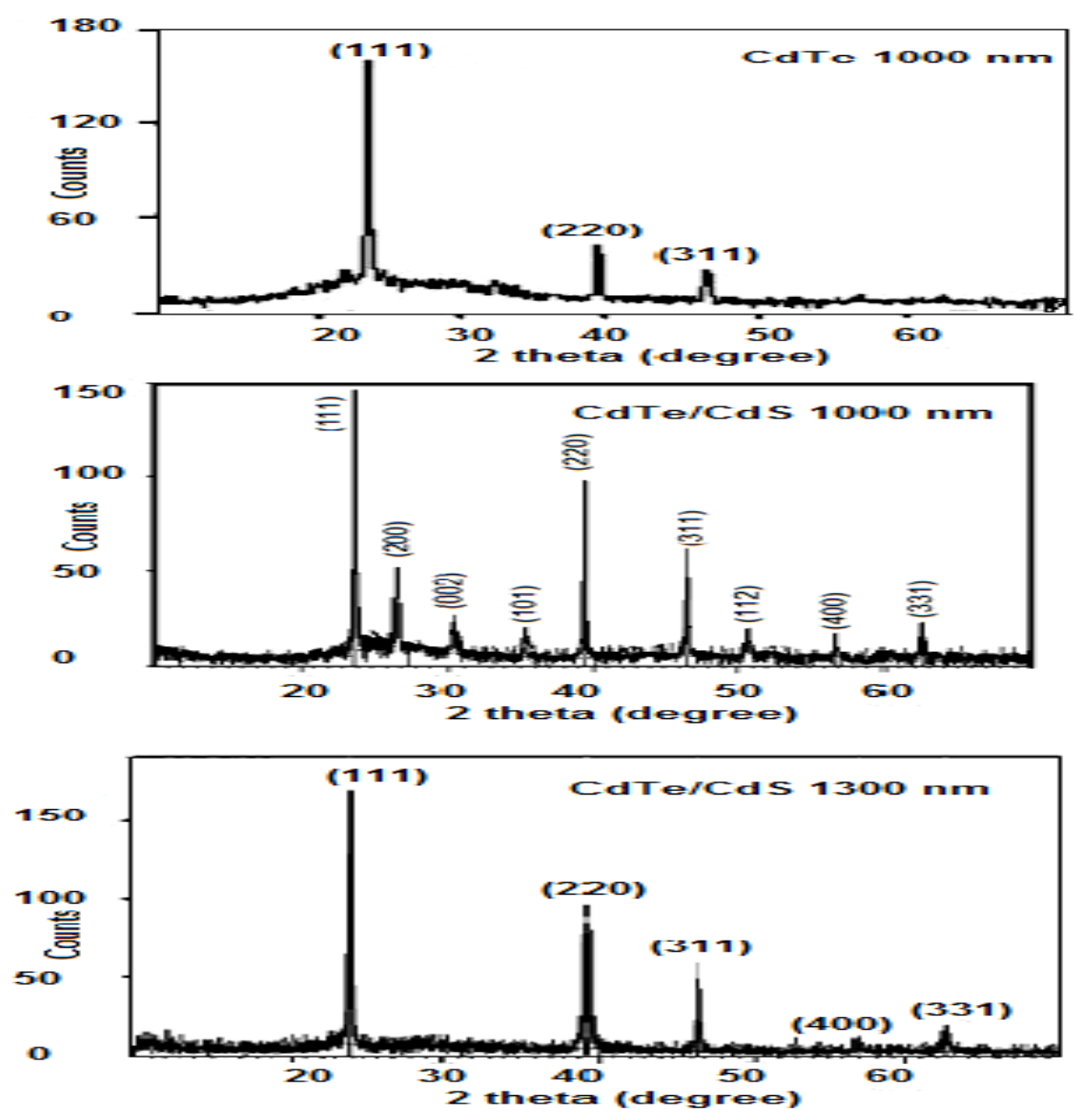

Figure 1. XRD spectra of (a) CdTe $1000 \mathrm{~nm}$ (b) CdTe/CdS 1000 nm (c) CdTe/CdS $1300 \mathrm{~nm}$
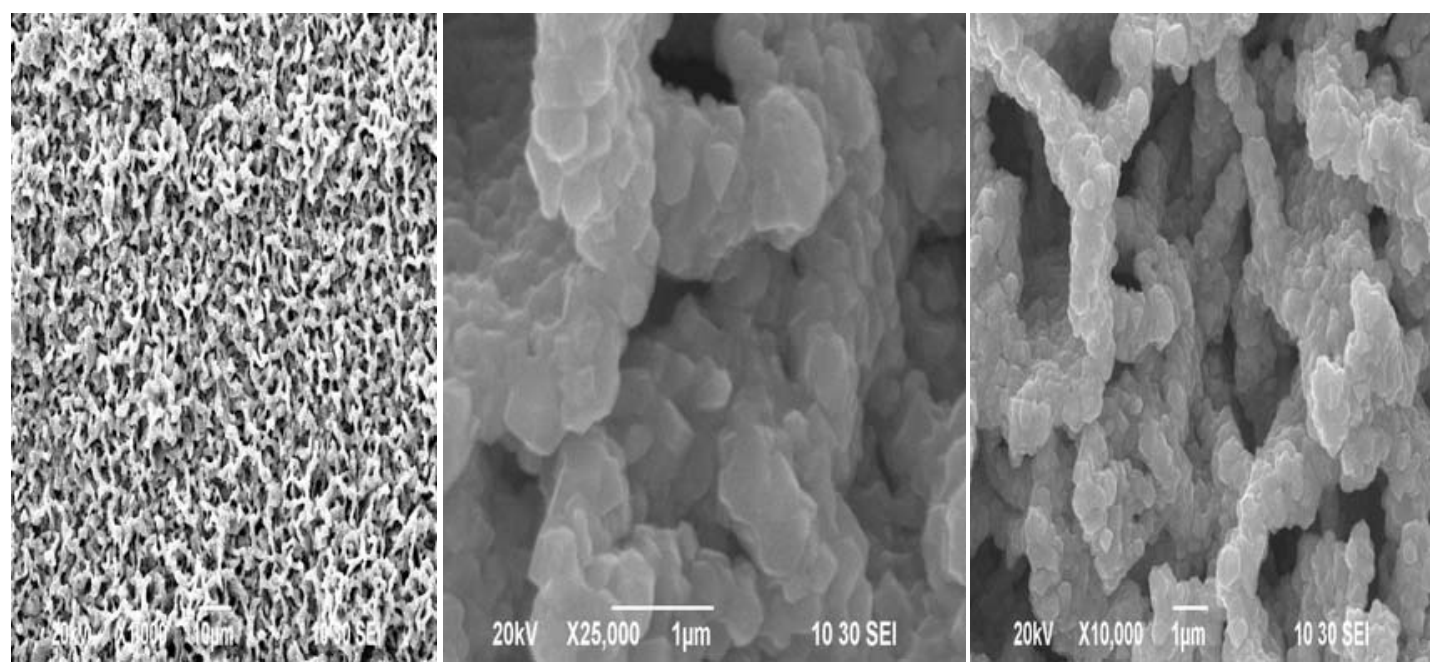

Figure 2. SEM image of CdTe thin film of thickness $1000 \mathrm{~nm}$ deposited on CdS thin film with magnification X25000 


\subsection{Surface Study of CdTe/CdS/FTO Thin Film}

The surface morphology of CdTe thin film deposited on a glass substrate observed under a scanning electron microscope is shown in figure 2. The crystallites of these films are regularly spiral shaped with a typical size of about $700 \mathrm{~nm}$. It is clear that the layer is not uniform and does not completely cover on the FTO substrate. As resolution (X 25000) increases a very few pinholes are observed clearly in the film. Individual grain boundary is not specifically visible rather grains are connected to one another like rope. This substrate characteristic is in agreement with the reported work [13]. The surface image suggested that CdS nucleates at these points and grow as columns normal to the substrate. The grains of the film are entangled due to deposit on top of CdS/FTO glass substrate and formed wide grain boundaries. This situation can be changed to a certain extent by using either thick CdS or CdTe layers or deposition of a buffer layer.

Table 1. Structural parameters of CdTe thin films

\begin{tabular}{|c|c|c|c|c|c|c|}
\hline $\begin{array}{c}\text { Sample } \\
\text { Name }\end{array}$ & $\begin{array}{l}\begin{array}{l}\text { Observed } 2 \theta \\
\text { (degree) }\end{array} \\
\end{array}$ & $\begin{array}{l}\text { Observed } \\
\left.\text { FWHM( }{ }^{\circ} 2 \theta\right)\end{array}$ & $\begin{array}{l}\text { Observed (d) } \\
(\mathrm{nm})\end{array}$ & $\begin{array}{l}\text { Standard } \\
\text { (d) (nm) }\end{array}$ & $\begin{array}{l}\text { Relative } \\
\text { intensity }\end{array}$ & $\begin{array}{l}\text { Plane } \\
\text { (hkl) }\end{array}$ \\
\hline & 23.8338 & 0.1378 & 0.3734 & 0.3742 & 100 & (111) \\
\hline & 26.6871 & 0.1574 & 0.3340 & 0.3355 & 22.96 & (200) \\
\hline & 30.3131 & 0.4723 & 0.2949 & 0.2906 & 7.52 & (002) \\
\hline $\mathrm{CdTe} / \mathrm{CdS}$ & 35.3960 & 0.2362 & 0.2536 & 0.2514 & 6.09 & (101) \\
\hline \multirow[t]{5}{*}{$1000 \mathrm{~nm}$} & 39.3840 & 0.1968 & 0.2288 & 0.2290 & 57.09 & (220) \\
\hline & 46.5042 & 0.2362 & 0.1953 & 0.1954 & 28.44 & (311) \\
\hline & 50.7031 & 0.4723 & 0.1801 & 0.1812 & 4.92 & (112) \\
\hline & 57.0181 & 0.9446 & 0.1615 & 0.1619 & 2.66 & (400) \\
\hline & 62.5877 & 0.5760 & 0.1483 & 0.1488 & 4.45 & (331) \\
\hline CdTe 1000 & 23.8525 & 0.1771 & 0.3731 & 0.3742 & 100 & (111) \\
\hline $\mathrm{nm}$ & 39.3353 & 0.2165 & 0.2291 & 0.2290 & 23.33 & (220) \\
\hline [1] & 46.4827 & 0.3840 & 0.1952 & 0.1954 & 13.38 & (311) \\
\hline $\mathrm{CdTe} / \mathrm{CdS}$ & 23.819 & 0.0984 & 3.735 & 0.3742 & 100 & (111) \\
\hline \multirow[t]{4}{*}{$1300 \mathrm{~nm}$} & 39.351 & 0.2362 & 2.290 & 0.2290 & 44.98 & (220) \\
\hline & 46.488 & 0.2755 & 1.953 & 0.1954 & 24.08 & (311) \\
\hline & 56.857 & 0.4723 & 1.619 & 0.1619 & 2.89 & (400) \\
\hline & 62.403 & 0.3840 & 1.487 & 0.1488 & 6.47 & (331) \\
\hline
\end{tabular}

\subsection{Optical Study of CdTe/CdS/FTO Thin Film}

Figure 3 shows the variation of transmittance of CdTe thin film of thickness $1000 \mathrm{~nm}$ deposited on Chemical Bath Deposited-CdS with photon wavelength varying in the range between $300 \mathrm{~nm}$ and $1500 \mathrm{~nm}$.

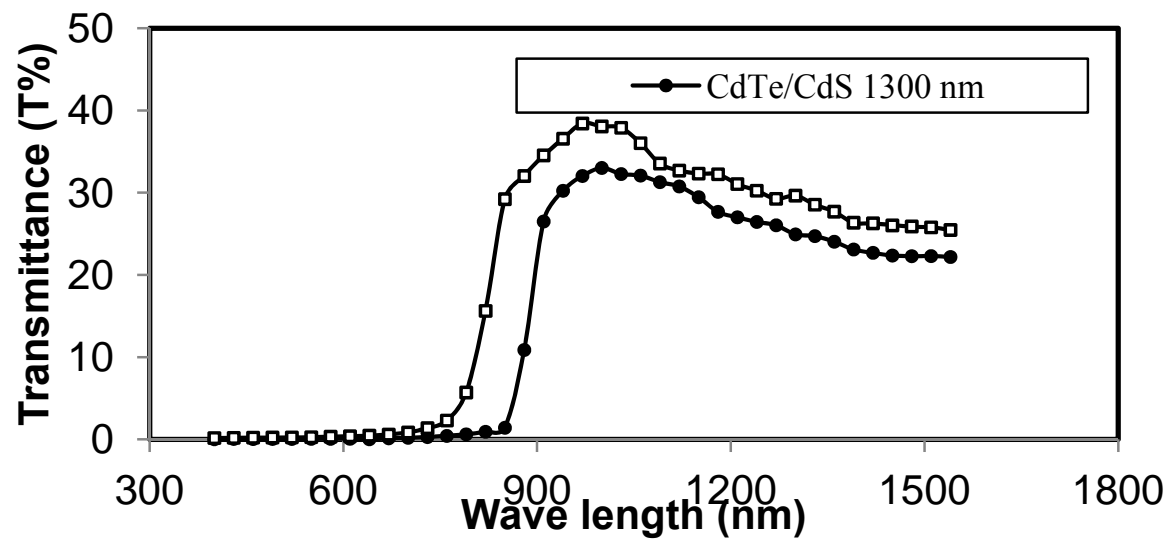

Figure 3. Transmittance variation of CdTe thin films with wavelength 


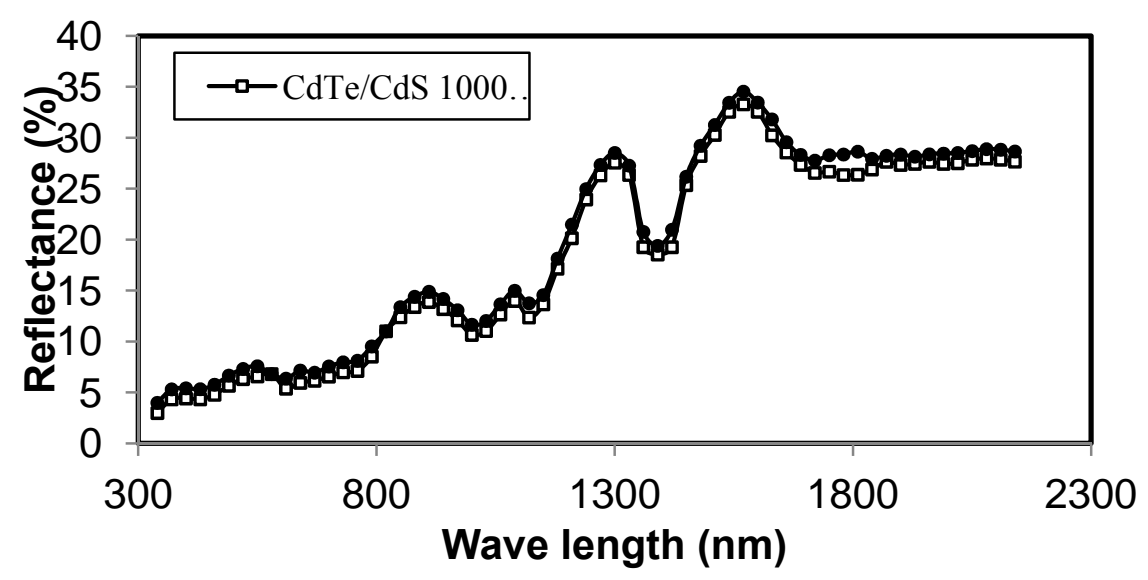

Figure 4. Reflectance variation of CdTe thin films

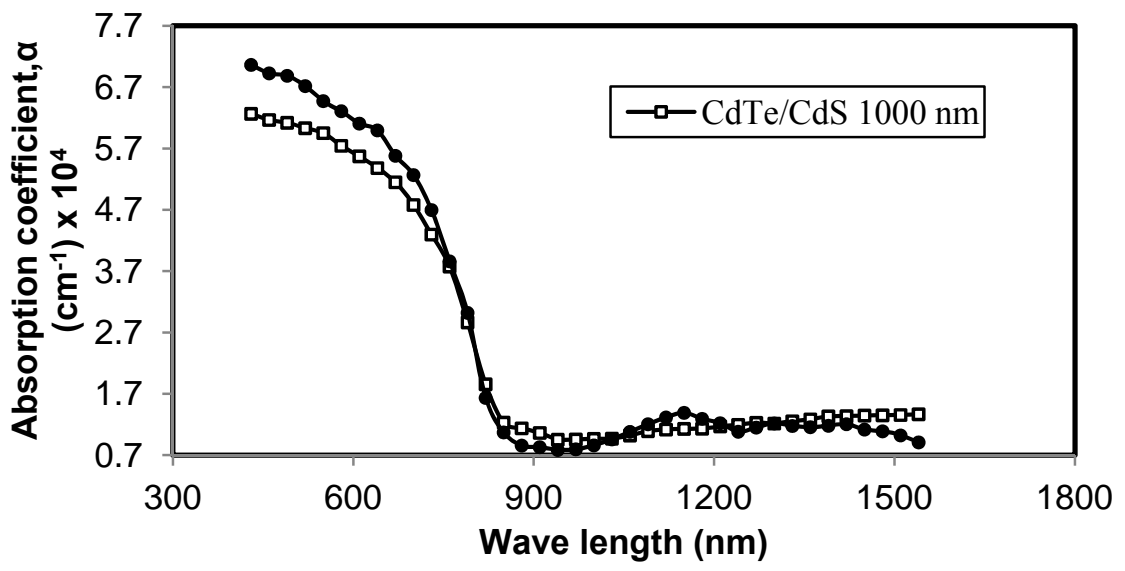

Figure 5. Absorption coefficient variation of CdTe thin films

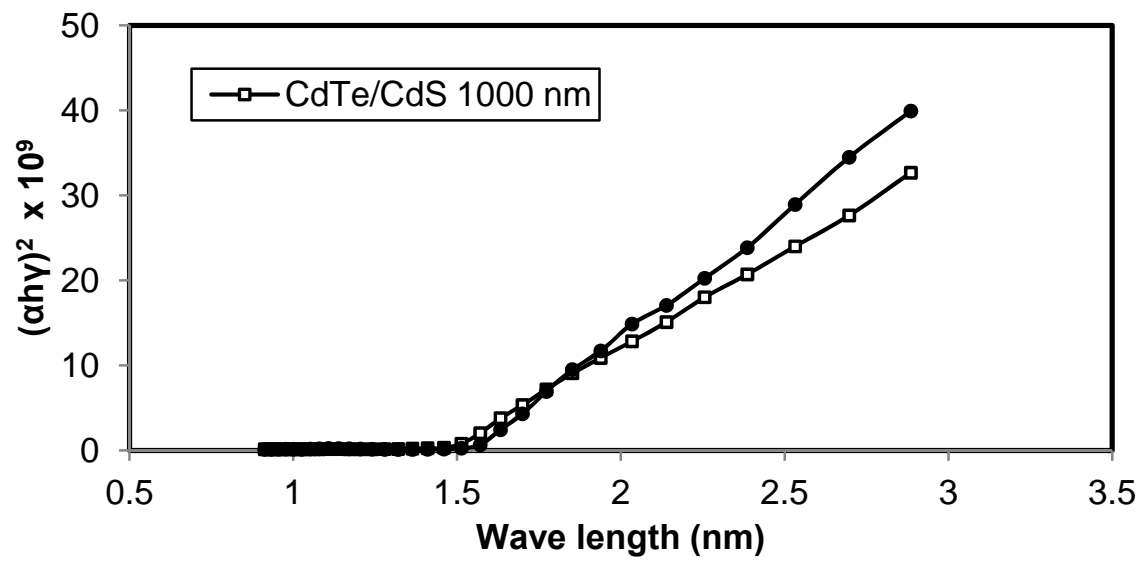

Figure 6. $(\alpha h v)^{2}$ vs photon energy (hv) plot of CdS/CdTe thin films

The figure showed consistent optical transparency in the spectral region between $1200 \mathrm{~nm}$ to 1500 $\mathrm{nm}$. High transmittance in a higher wavelength region and a sharp absorption edge is observed in the films. The absorption edge is interrelated to the optical band gap which agrees with reported work. The transmittance falls steeply with decreasing wavelength from $900 \mathrm{~nm}$ to about $800 \mathrm{~nm}$. The decrease in transmission could arise due to the increase in absorbance associated with change in surface microstructure as reported by Chandramohanet. Figure 4 shows the variation of reflectance with photon wavelength in the 
range $300 \mathrm{~nm}$ to $1500 \mathrm{~nm}$. From figure 4 , it is observed that reflectance falls with decreasing wavelength (300$880 \mathrm{~nm})$. The variation of absorption co-efficient $(\alpha)$ with wavelength in the range varying between $300 \mathrm{~nm}-$ $1500 \mathrm{~nm}$ of CdTe thin films is shown in figure 5. From figure 5, it is seen that in the shorter wavelength the absorption co-efficient exhibits higher values, these values of $\left(\alpha>10^{4}\right)$ means there is a large probability of the allowed direct transition which agrees with the work of Mottet. Al [13]. Value of absorption co-efficient decreases steeply with increase in wavelength and remains consistent at higher wavelength. The low absorption co-efficient makes CdTe films useful for optical components in high laser window and multispectral applications, providing good imaging characteristic.

In figure $6,(\alpha h v)^{2}$ is plotted against photon energy (hv) to find the band gap energy of CdTe thin film. The linear dependence showed by $(\alpha h v)^{2}$ with photon energy $(h v)$ indicates that the transmission is direct. The direct band gap energies of the films are determined by extrapolating the straight portion to the energy axis. Band gap is found $1.53 \pm 0.1 \mathrm{eV}$ by extrapolation of data point which is very close to standard value of $1.5 \mathrm{eV}$. Absorption coefficient is used to describe the reduction in intensity of light in a medium as a function of distance. The energy gap in a semiconductor is responsible for the fundamental optical absorption edge. The fundamental absorption process is one in which a photon is absorbed and an electron is excited from an occupied valence band state to an unoccupied conduction band state, if photon energy is less than the gap energy, then the electron will not be absorbed. Such inter band absorption process is possible only if the photon energy is higher than the band gap energy.

\section{CONCLUSIONS}

CdTe thin film was successfully deposited on CdS/FTO substrate using thermal evaporation method. The structural study of the film showed that the film is polycrystalline in nature and crystalinity is improved due to CdS/FTO layer. The surface image of the film concluded that the charge carrier mobilities along these columnar type materials have highest possible values and the grain boundary scattering becomes minimal during PV activity across the device structure. The films showed $42 \%$ transparency, 32\% reflectance and high absorption co-efficient $\left(\alpha>10^{4}\right)$. The optical band gap of the film was found $1.53 \mathrm{eV}$. These result revealed that $\mathrm{CdTe}$ layer could be suitable as absorber layer for $\mathrm{CdTe} / \mathrm{CdS}$ heterojunction solar cell structure.

\section{REFERENCES}

[1] K.M.A. Hussain, Z.H. Mahmood, Ishtiaque M Syed, T.Begum, T. Faruqe, and J. Parvin, "Thermal vacuum deposition of cadmium telluride thin films solar cell material".

[2] A.M.D. Ede, E.J. Morton, P. DeAntonis, Thin film CdTe for imaging detector applications. Nuclear Instruments and Methods in Physics Research A 458 (2001) 7-11.

[3] Katlander, J., Bargholtz, Chr, Batres-Estrada, G. and Behrooz, K. (2006)., "Development of Methods to Use CdTe Detectors in Field Measurements", Journal of Physics Conference Series, Vol. 41 pp 523-526.

[4] Lovergine, N., Prete, P., Tapfer, L., Marzo, F. and Mancin, A. I. (2005), "Hydrogen Transport Vapor Growth and Properties of Thick CdTe Epilayers for RT X-ray Detector Applications", Cryst Res Tech. Vol. 40 pp 1018-1023.

[5] K.M.A. Hussain, T. Faruqe, J.Parvin, S Ahmed, Z. H. Mahmood \& Ishtiaque M. Syed, "Study of CdTe Nuclear Detector Material In Thin Film Form Using Thermal Evaporation Method, Malaysian Journal of Medical and Biological Research (MJMBR), Vol. 2 No. 3 (2015).

[6] K.M.A. Hussain, T. Begum, Z.H. Mahmood, Ishtiaque M. Syed, S. Ahmed, "Study of thermally deposited CdS thin films for CdTe thin film solar cell application”, International Journal of Nanoscience and Nanoengineering. 2014; 1(2): 34-38.

[7] Laxman Gouda, Yelameli Ramesh Aniruddha, Sheela K. Ramasesha, Correlation between the Solution Chemistry to Observed Properties of CdTe Thin Films Prepared by CBD Method. Journal of Modern Physics, 3 (2012) 18701877.

[8] A. Romeo, D.L. Batzner, H. Zogg, C. Vignali", A.N. Tiwari. Influence of CdS growth process on structural and photovoltaic properties of CdTe/CdS solar cells Solar Energy Materials \& Solar Cells, 67 (2001) 311-321.

[9] B. Hymavathi, B. Rajesh Kumer, T. Subba Rao. Invettigations of optoelectronic properties of DC reactive magnetron sputtered CdTe thin films. Chalcogenide Letters, 10- 6 (2013) $209-216$.

[10] E.R. Shaaban, N. Afify, A. El-Taher, Effect of film thickness on microstructure parameters and optical constants of CdTe thin films. Journal of Alloys and Compounds, 482 (2009) 400-404.

[11] S.S. Patil and P.H. Pawer. "Effects of thickness on the structural and optical properties of thermally evaporated CdTe thin films, J. Chemical, Biological and Physical Sciences,2-2 (2012) 968-978.

[12] S. Chandramohan, R. Sathyamoorthy, P. Sudhagar, D. Kanjilal, D. Kabiraj, K. Asokan, Structural and photoluminescence properties of swift heavy ion irradiated CdS thin films. Thin Solid Films, 516 (2008) 55085512.

[13] Mott M. and Davis E. Electronic Process in Non-Crystalline Materials. 2nd ed.University Press Oxford, 1979. 